\title{
The Effects of Moringa Oleifera Lam. Leaves Extract on Osteogenic Differentiation of Porcine Bone Marrow Derived Mesenchymal Stem Cells
}

\author{
Kulisara Marupanthorn ${ }^{1}$, and Wisit Kedpanyapong ${ }^{2}$
}

\begin{abstract}
Moringa oliefera Lam., the Asian herbal plant, has various uses, such as anti-oxidantion, and anti-inflammation. We have investigated the effect of Moringa oleifera Lam. leaves extract on osteogenic differentiation of porcine bone marrow derived mesenchymal stem cells. The potential of MSC for osteogenic differentiation has been well documented in many animal models especially on rodents. Despite the increasing importance of the pig as a large animal model. Previous studies have shown the benefits of Moringa oliefera leaves on anti-osteoporotic effect in osteoblastic cells. Therefore, this study aims to examine the effect of 100, 200, and $300 \mathrm{ng} / \mathrm{ml}$ of ethanolic extract of Moringa oleifera Lam. leaves on osteogenic differentiation of porcine MSCs derived from bone marrow. The degree of osteogenic differentiation after Moringa oleifera Lam. leaves extract treatment was assessed by alkaline phosphatase (ALP) expression and ALP activity. The results showed that ethanolic extract of Moringa oleifera Lam. leaves enchanced osteogenic differentiation capacity of porcine bone marrow derived MSCs as demonstrated by increased ALP staining and ALP activity. The enhancement of osteogenic differentiation capacity of MSCs by those of Moringa oleifera Lam. leaves extract leads to the potential for using those for bone regeneration in pre-clinical models and bone alternative medicine.
\end{abstract}

Keywords-Moringa oleifera Lam. leaves, porcine bone marrow derived mesenchymal stem cells, osteogenic differentiation.

\section{INTRODUCTION}

Mesenchymal stem cells (MSC) are plastic adherent stromal cells found in special tissues and organs. With the capacity for self-renewal and multi-lineage differentiation, they are considered a promising cell source for tissue engineering, as they are easily accessible and not associated with ethical issues in relation to their use (1). It has been widely accepted that MSC based therapy has shown significant improvement of tissue regeneration in pre-clinical models and clinical trials. Despite the recent progress in MSC-based tissue regeneration in the last few decades, a major challenge remains how to restore new bone formation following disease or insult with the high quality and the bone volume that meet the needs of the body $(2,3)$.

Kulisara Marupanthorn ${ }^{1}$ is with the Rajamangala University of Technology Suvarnabhumi, Phra Nakorn Sri Ayutthaya, 13000 THAILAND

Wisit Kedpanyapong ${ }^{2}$, is with the Rajamangala University of Technology Suvarnabhumi, Phra Nakorn Sri Ayutthaya, 13000 THAILAND.
Purified and expanded MSC from various species have been shown to differentiate along osteogenic (4), chondrogenic (5),

and adipogenic (6). Ringe and co-worker (7) established a protocol for the isolation of porcine MSC to compare their phenotype and their multilineage potential with human MSC. They report that the techniques used for osteogenic differentiation of porcine MSCs, which may serve the increasing demand for stem and progenitor cells in tissue engineering. As a result of the presented similarities between porcine and human MSC, porcine MSC are likely to be considered as a valuable model system for skeletal research.

After conducting several experiments on Moringa oleifera Lam. leaves (MOL) extract and understanding its osteoprotective effect, it was learned that this plant is having miraculous effect on bone integrity and it potently improve osteogenesis. Various workers have indicated that this plant is having various phytochemicals, especially phytoestrogens which can have positive effect on bone. Recent work by Zhang and co-workers (8) has shown that flavonoids can stimulate osteoblastic proliferation and differentiation. In another study, Vali and his collogues (9) also proved that Epigallocatechin-3-gallate like flavonoids induce bone mineralization and bone nodule formation. As MOL extract is rich in various flavonoids, one can speculate about osteoblastogenic potential of this plant $(10,11)$. In the present study, we examined whether MOL extract treated porcine bone marrow derived mesenchymal stem cells is capable of accelerating the osteogenic differentiation in vitro.

\section{MATERIALS AND METHODS}

\section{A. Preparation of Extract}

Leaves of Moringa oleifera Lam. were obtained in Phra Nakorn Sri Ayutthaya. Dried powder was prepared by drying Moringa oleifera Lam. in oven at $50^{\circ}$ C. $100 \mathrm{gm}$ dried powder of each component was extracted with $500 \mathrm{ml}$ methanol in Soxhlet's apparatus for 48 hours . Methanolic extract was dried on water bath at $55^{\circ} \mathrm{C}$. The leaves extract was freeze dried and stored at $-70^{\circ} \mathrm{C}$. Working solution was prepared by dissolving the extract in phosphate buffered saline (PBS). 


\section{B. Cell isolation and culture}

Isolation and culture of porcine bone marrow derived mesenchymal stem cells ( $p$ BM-MSCs) from adult pig bone marrow. Bone marrow was aspirated from finished pig $(\mathrm{n}=$ 3; 5-6 months of age) collected at a local slaughter house. The marrow was drawn from femoral marrow cavity into syringes containing $1000 \mathrm{U}$ heparin. Bone marrow samples were washed twice with PBS and twice with DMEM. Subsequently, the cells were washed twice with washing buffer and cultured in completed medium containing Dulbecco's Modified Eagle's Medium (DMEM; GibcoBRL, USA) supplemented with $10 \%$ fetal bovine serum (FBS; Invitrogen, USA), $2 \mathrm{mM}$ L-glutamine (GibcoBRL, USA), 100 $\mathrm{U} / \mathrm{ml}$ penicillin and $100 \mu \mathrm{g} / \mathrm{ml}$ streptomycin. The medium was changed every 3-4 days. The plastic adherent fibroblastlike cells or so-called $p$ BM-MSCs (about $80-90 \%$ confluence) were sub-cultured using $0.25 \%$ trypsin-EDTA (GibcoBRL, USA) and replated at density of $1 \times 10^{5} \mathrm{cell} / \mathrm{cm}^{2}$ for further expansion.

C. Cell proliferation assay in vitro

The effect of 100, 200, 300, and $400 \mathrm{ng} / \mathrm{ml}$ ethanolic extract of MOL on $p$ BM-MSCs proliferation was assessed using the MTT (3-[4,5-dimethylthiazol-2-yl]-2, 5-diphenyl tetrazolium bromide) assay. Ex vivo expanded $p$ BM-MSCs were seeded at passage three $\left(1.0 \times 10^{4}\right.$ cells/ well $)$ in triplicate using a 96-well flat-bottom plate (Costar, Cambridge, MA, USA) and maintained in $100 \mu \mathrm{l}$ medium with 100,200 , and $300 \mathrm{ng} / \mathrm{ml}$ ethanolic extract of MOL or standard culture medium for five days. Cells were treated with $5 \mathrm{mg} / \mathrm{ml}$ of MTT reagent (Sigma-Aldrich, St. Louis, MO, USA) and incubated at $38{ }^{\circ} \mathrm{C}$ for $4 \mathrm{~h}$. After cells were washed twice in PBS and treated with dimethyl sulfoxide, the absorbance in each well was measured at a wavelength of 490 $\mathrm{nm}$ using an automatic enzyme-linked immunosorbent assay (ELISA) reader (ELx800; BioTek Instruments Inc., Winooski, VT, USA).

\section{Osteogenic differentiation}

$p$ BM-MSCs were plated into $35-\mathrm{mm}$ tissue culture dishes and cultured in completed medium at $38^{\circ} \mathrm{C}$ for $24 \mathrm{~h}$. Subsequently, the cells were cultured in osteogenic differentiation medium containing DMEM supplemented with $10 \%$ FBS, $100 \mathrm{U} / \mathrm{ml}$ Penicillin, $100 \mu \mathrm{g} / \mathrm{ml}$ Streptomycin, $0.1 \mu \mathrm{M}$ dexamethasone (Sigma,USA) and $50 \mu \mathrm{g} / \mathrm{ml}$ ascorbic acid (Sigma, USA) in the 100, 200, and $300 \mathrm{ng} / \mathrm{ml}$ ethanolic extract of MOL. On day 7 of culture, $10 \mathrm{mM} \beta$ glycerophosphate (Sigma, USA) was added into each cultured dishes. Cells were harvested on 3, 7, and 14 of cultures for measuring alkaline phosphatase (ALP) activity using 5Bromo-4-chloro-3-indolyl phosphate/nitro blue tetrazolium (NBT/BCIP; Sigma, USA) as a substrate. Cells cultured in completed medium served as a control and were treated in pararell to the experiment.

The quantitative alkaline phosphatase activity assay was measured using SensoLyte ${ }^{\circledR} p$ NPP alkaline phosphatase assay kit (AnaSpec, USA). Briefly, MSCs were cultured for 3, 7, and 14 days. ALP activity was measured by using microplate reader (BioTex, USA) using absorbance at $405 \mathrm{~nm}$. The ALP activity in each sample was calculated by comparing the measure OD values against a standard curve generated from $0-10 \mathrm{ng} / \mathrm{ml}$ of alkaline phosphatase standard solution. Each assay condition was done in triplicate and normalized with the concentrations oftotal cellular proteins using Bradford assay (Bio-Rad, USA).

\section{E. Statistical analysis}

Data analysis was carried out using SPSS10 statistical software. Data points are reported as the mean \pm standard deviation (SD) or mean \pm standard error of the mean (SEM). Statistical significance of $(*) p \leq 0.05$ was determined using the unpaired Student t-testor one-way analysis of variance (ANOVA). Statistical analysis was performed as described using at least three biological replicates unless otherwise stated.

\section{RESULTS}

\section{A. Culture of $p B M-M S C s$}

After primary culture, $p$ BM-MSCs exhibited a morphologically homogeneous spindle-like population as shown in Figure 1. During the culture period, primary or passaged UC-MSCs displayed fibroblast-like morphological features, without visible morphologic alteration.

$B$. The effect of ethanolic extract of Moringa oleifera Lam. leaves on $p B M-M S C$ s proliferation

$p$ BM-MSCs were treated with ethanolic extract of MOL at various concentrations $(50,100,200,300$ and $400 \mathrm{ng} / \mathrm{ml})$ before the rate of cell proliferation was examined with the MTT assay. Ethanolic extract of MOL at $100 \mu \mathrm{g} / \mathrm{ml}$ was shown to enhance $p$ BM-MSCs proliferation. Ethanolic extract of MOL at high concentrations $(400 \mathrm{ng} / \mathrm{ml})$ seemed to display an inhibitory effect on cell proliferation (Fig.2).

C. Ethanolic extract of Moringa oleifera Lam. leaves stimulates the osteogenesis of pBM-MSCs in vitro

To determine the effect of the ethanolic extract of MOL on the osteogenic differentiation of $p$ BM-MSCs, the cells were cultured in osteogenic differentiation medium in the 100,200 , and $300 \mathrm{ng} / \mathrm{ml}$ ethanolic extract of MOL for 14 days (Fig. 3). After induction for 7 days, the expression of ALP was observed in $p$ BM-MSCs cultured with osteogenic differentiation medium in the absence of ethanolic extract of MOL. Interestingly, treatment with $300 \mathrm{ng} / \mathrm{ml}$ ethanolic extract of MOL during osteogenic differentiation increased the ALP expression. In addition, $p$ BM-MSCs treated with $300 \mathrm{ng} / \mathrm{ml}$ ethanolic extract of MOL for 14 days exhibited higher ALP expression (Fig. 3O) as compared to $p \mathrm{BM}$ MSCs treated with $300 \mathrm{ng} / \mathrm{ml}$ ethanolic extract of MOL for 7 days. The result of alkaline phosphatase staining also indicated the higher expression of alkaline phosphatase in $p$ BM-MSCs treated with ethanolic extract of MOL for 14 days as compared to the 100, 200, and control groups respectively (Fig. 3).

\section{ALP activity in $p B M-M S C s$}

The activity of intracellular ALP in $p$ BM-MSCs was also quantitative assessed using colorimetric enzymatic assay at day 3,7 , and 14 . The results demonstrated that the $p$ BM- 
MSCs cultured in osteogenic differentiation medium supplemented with $300 \mathrm{ng} / \mathrm{ml}$ ethanolic extract of MOL showed a clear superiority compared to the others (MSCs cultured in complete medium and MSCs cultured in osteogenic differentiation medium) (Fig. 4). As early as 14 days after ethanolic extract of MOL induction, ethanolic extract of MOL induced $p$ BM-MSCs had about 2.5 folds increase in alkaline phosphatase activity. $(p<0.05)$.
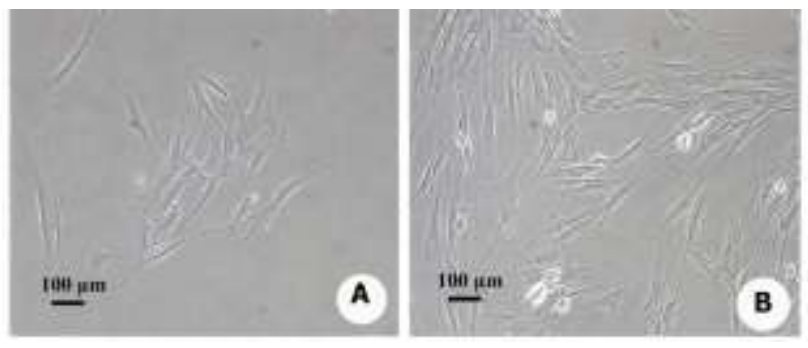

Fig 1. Morphology of primary cultured $p$ BM-MSCs. A: Spherical-shaped cells at day 7 after the initial seeding; B: Adherent cells at day 3 of passage 3 . Scale bar $=100 \mu \mathrm{m}$.

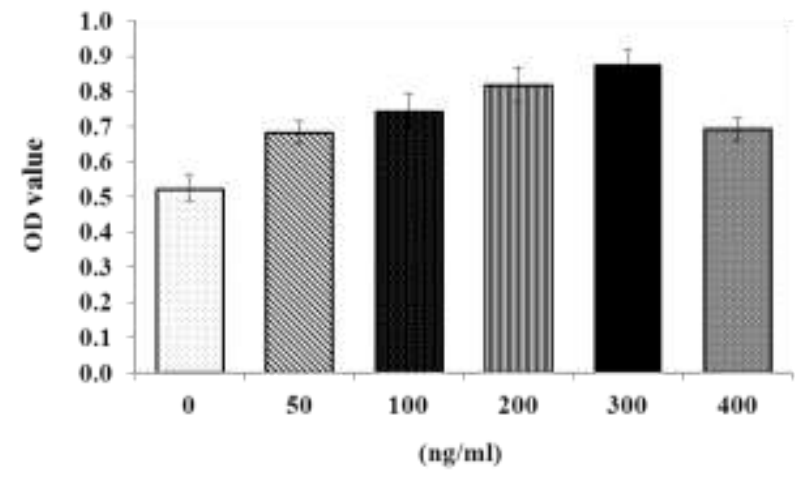

Fig. 2. Ethanolic extract of MOL at 50, 100, 200, and 300 $\mathrm{ng} / \mathrm{ml}$ enhances $p \mathrm{BM}-\mathrm{MSC}$ proliferation, while ethanolic extract of Moringa oleifera Lam. leaves at high concentrations displayed an inhibitory effect on cell proliferation, shown by MTT assay.
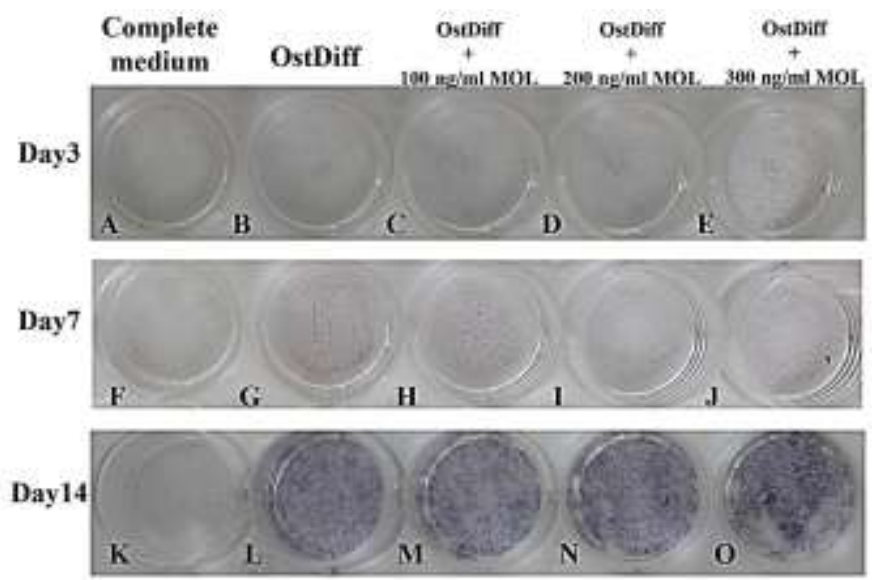

Fig. 3. The expression of alkaline phosphatase in $p$ BM-MSCs cultured in osteogenic differentiation medium supplemented with 100, 200, and $300 \mathrm{ng} / \mathrm{ml}$ MOL for 3 (C, H, M), 7 (D, I, N), and 14 days (E, J, O, respectively) in comparison to those of MSCs cultured in osteogenic medium without MOL (B, G, L, respectively). $p \mathrm{BM}-\mathrm{MSC}$ cultured in DMEM supplemented with $10 \%$ FBS served as negative control (A, F, K, resepectively).

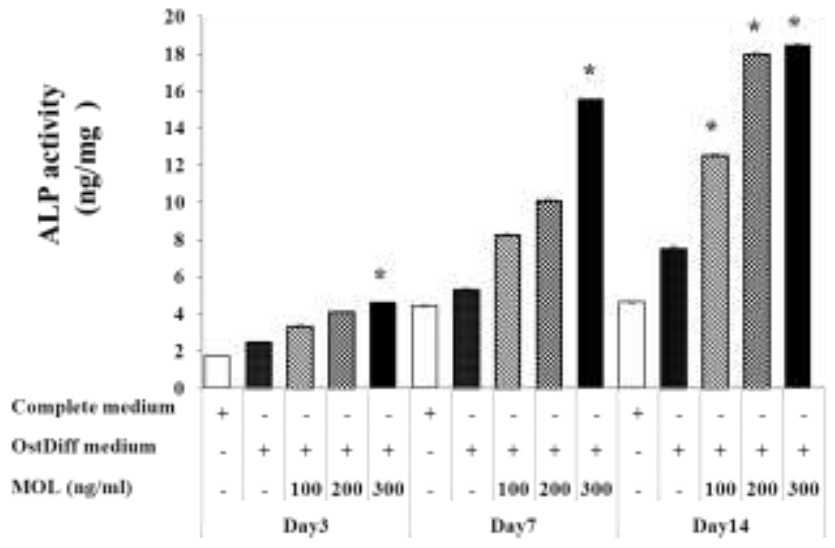

Fig 4.: Alkaline phosphatase activity of MOL induced osteogenic differentiation of $p$ BM-MSCs. Data are expressed as mean \pm SEM. $* p<0.05$ : significant difference in comparison to MSCs cultured in osteogenic differentiation medium.

\section{DISCUSSION}

The multi-lineage differentiation potential of MSCs has been extensively studied and culturing conditions for in vitro differentiation has been established. Although much progress has been made regarding the osteogenic differentiation process in the last decade, the restricted quantity and quality of functional osteocytes are the main obstacles for the therapeutic application. Exploratory for the new mediators that are able to enhance the osteogenic differentiation capacity of MSCs is thus necessary. This is the first study demonstrated that MOL treatment could enhance the osteogenic differentiation of $p \mathrm{BM}-\mathrm{MSCs}$ as demonstrated by the increased expression of alkaline phosphatase activity and enhances ALP expression.

Treatment with MOL increased alkaline phosphatase activity as evidenced on day 7 and day 14 after osteogenic induction. This result is similar to the previous study which indicated that feeding of MOL to bilaterally ovariectomised rat can reduced bone loss (12). Moreover, methanolic extracts of MO components were found to have significant osteoblast stimulating property on osteoblastic cells (13). Due to flavonoid in ethanolic extract of MOL could induce $p$ MSCs derived from bone marrow to undergo osteogenic differentiation (14).

As discussed by Ringe and co-worker (7), porcine MSC from bone marrow have been isolated routinely, and the mesenchymal differentiation pattern exhibits a reproducible and stable phenotype. MSC may be a source of easily accessible mesenchymal progenitor cells for the evolving field of tissue engineering to regenerate bone, cartilage, tendon, and adipose tissue, autologously. Due to the similarity between porcine and human MSC, swine may provide a useful animal model system to study and evaluate tissueengineered applications based on mesenchymal stem cells. 


\section{REFERENCES}

[1] Cao Y, Xiong J, Mei S, Wang F, Zhao Z, Wang S, et al. Aspirin promotes bone marrow mesenchymal stem cell-based calvarial bone regeneration in mini swine. Stem Cell Res Ther. 2015;6:210. https://doi.org/10.1186/s13287-015-0200-4

[2] Bianco P, Riminucci M, Gronthos S, Robey PG. Bone marrow stromal stem cells: nature, biology, and potential applications. Stem Cells. 2001;19(3):180-92.

https://doi.org/10.1634/stemcells.19-3-180

[3] Owen M, Friedenstein AJ. Stromal stem cells: marrow-derived osteogenic precursors. Ciba Found Symp. 1988;136:42-60.

[4] Jaiswal N, Haynesworth SE, Caplan AI, Bruder SP. Osteogenic differentiation of purified, culture-expanded human mesenchymal stem cells in vitro. J Cell Biochem. 1997;64(2):295-312. https://doi.org/10.1002/(SICI)1097-4644(199702)64:2<295::AIDJCB12>3.0.CO;2-I

[5] Mackay AM, Beck SC, Murphy JM, Barry FP, Chichester CO, Pittenger MF. Chondrogenic differentiation of cultured human mesenchymal stem cells from marrow. Tissue Eng. 1998;4(4):415-28. https://doi.org/10.1089/ten.1998.4.415

[6] Pittenger MF, Mackay AM, Beck SC, Jaiswal RK, Douglas R, Mosca JD, et al. Multilineage potential of adult human mesenchymal stem cells. Science. 1999;284(5411):143-7. https://doi.org/10.1126/science.284.5411.143

[7] Ringe J, Kaps C, Schmitt B, Buscher K, Bartel J, Smolian H, et al. Porcine mesenchymal stem cells. Induction of distinct mesenchymal cell lineages. Cell Tissue Res. 2002;307(3):321-7. https://doi.org/10.1007/s00441-002-0525-z

[8] Zhang DW, Cheng Y, Wang NL, Zhang JC, Yang MS, Yao XS. Effects of total flavonoids and flavonol glycosides from Epimedium koreanum Nakai on the proliferation and differentiation of primary osteoblasts. Phytomedicine. 2008;15(1-2):55-61. https://doi.org/10.1016/j.phymed.2007.04.002

[9] Vali B, Rao LG, El-Sohemy A. Epigallocatechin-3-gallate increases the formation of mineralized bone nodules by human osteoblast-like cells. $\mathbf{J}$ Nutr Biochem. 2007;18(5):341-7. https://doi.org/10.1016/j.jnutbio.2006.06.005

[10] Mbikay M. Therapeutic Potential of Moringa oleifera Leaves in Chronic Hyperglycemia and Dyslipidemia: A Review. Front Pharmacol. 2012;3:24. https://doi.org/10.3389/fphar.2012.00024

[11] Kahkonen MP, Hopia AI, Vuorela HJ, Rauha JP, Pihlaja K, Kujala TS, et al. Antioxidant activity of plant extracts containing phenolic compounds. J Agric Food Chem. 1999;47(10):3954-62. https://doi.org/10.1021/jf9901461

[12] Sanganna C. Burali Vk, Om sai sravani, S. L. Patil. THE BENEFICIAL EFFECT OF ETHANOLIC EXTRACT OF MORINGA OLEIFERA ON OSTEOPOROSIS. International Journal of Pharmaceutical Applications. 2010;1(1):50-8.

[13] Chirag Patel AR, Pragna Parikh3. The anti-osteoporotic effect of Moringa oliefera on osteoblastic cells: SaOS 2. Journal of Pharmacy and Biological Sciences 2013;5(2):10-7. https://doi.org/10.9790/3008-0521017

[14] Anwar F, Latif S, Ashraf M, Gilani AH. Moringa oleifera: a food plant with multiple medicinal uses. Phytother Res. 2007;21(1):17-25.

https://doi.org/10.1002/ptr.2023 